\title{
Research of Bovine Bone Collagen/cellulose Nanofibers-nanohydroxyapatite Biological Composite
}

\author{
JIN Shenglang ${ }^{1, \text { a }}$ \\ ${ }^{1}$ Tourism College, Huangshan University, Huangshan 245021, China \\ ajinshenglang@163.com
}

\begin{abstract}
Objective: Different biomaterials have been used as scaffolds for bone tissue engineering. The purpose of the study was to analyze the effect of bovine bone collagen to the porosity, water retention, degradation rate and biomechanical characteristics of composite scaffolds. Methods: Bovine bone collagen solution was mixed with cellulose nanofibers solution, and then the mixture was added a certain quality of hydroxyapatite. We divided the mixture into two groups according to the different bovine bone collagen solution mass fraction: No.1 ( $0 \%$ bovine bone collagen), No.2 (50\% bovine bone collagen). The surface structure and the pore size was observed under the Scanning electron microscopic. Then we calculated the porosity, degradation rate, water content and biomechanical properties. Results: Two groups of scaffold materials showed a multi-pore structure. The average pore size were $133.4 \pm 13.5 \mu \mathrm{m}$ and $221.7 \pm 16.8 \mu \mathrm{m}$. The porosity was $(91.65 \pm 1.75) \%$ and $(85.42 \pm 1.48) \%$. Statistical analysis showed that two groups of material porosity difference were statistically significant $(P<0.05)$. The degradation rates of two groups of scaffold materials at six weeks were $(60.25 \pm 1.81) \%$ and $(23.16 \pm 1.027) \%$. Statistical analysis showed that the degradation rate of the material differences between the two groups were statistically significant $(P<0.05)$. Water content of two groups of scaffold materials was $(97.44 \pm 0.98 \%$ and $(91.36 \pm 0.77) \%$. Statistical analysis showed that the water content of the material differences between the two groups were statistically significant $(P<0.05)$. Biomechanical properties of the second group increased significantly. Conclusion: It could be seen from the experimental data that bovine bone collagen could increase the pore size, improved stability to degradation and the biomechanical strength of materials. Therefore, the biocomposite studied has several characteristics considered as ideal for its use as a scaffold for osteoconduction and osteoinduction.
\end{abstract}

Keywords: bovine bone collagen; cellulose nanofibers; nanohydroxyapatite; biological composite

\section{Introduction}

With an increase of the mean population age, the development and optimization of bone regeneration techniques represents a major clinical need for many countries ${ }^{[1]}$. Auto grafts 
have limitations due to the necessity of an additional surgery, limited donor bone supply, an atomical and structural problems and inadequate resorption rate during healing. Allografts have the disadvantage of a potential immune response, transmitting diseases, and they may induce the loss of osteoinduction ${ }^{[2]}$. With the rapid development of science and tissue engineering, bone tissue repair research has made great progress in recent years. Cellulose nanofibers is widely used in bone tissue engineering because of its good hydrophilicity and biodegrad-ability under normal physiological conditions ${ }^{[3]}$. Cellulose nanofibers could increase the mechanical strength of the stent and could be formed in a short time frame. It is easier to adjust the porosity of the bracket.

Hydroxyapatite (HA), $\left[\mathrm{Ca}_{10}\left(\mathrm{PO}_{4}\right)_{6}(\mathrm{OH})_{2}\right]$, is one of the frequently used bioceramics for bone and dental tissues reconstitution. It has excellent biocompatibility with hard tissues, and high osteoconductivity and bioactivity despite its low degradation rate, mechanical strength and osteoinductive potential. It has neither antigenicity nor cytotoxicity ${ }^{[4]}$. Collagen is biocompatible,bio degradable and osteoinductive, actin $\mathrm{g}$ as an excellent delivery system for bone morphogenetic proteins (BMPs). When associated to HA particles forming a biocomposite, it prevents the HA dispersion in implants,resul ting in an easily molded biomaterial. Bovine collagen antigenicity may be reduced by treatments with pepsin and strong alkaline solutions, and physicochemical agents that induce cross-linking of collagen ${ }^{[5]}$.

Therefore, in the medical field, bovine bone collagen could play an important role in bone repair and tissue engineering. For example, bovine bone collagen and hydroxyapatite scaffolds prepared by mixing can increase the mechanical properties of the stent, and it could be used as a bone repair and reconstruction of bone. In this study, we analyzed the effect of bovine bone collagen to the porosity, water retention, degradation rate and biomechanical characteristics of composite scaffolds, providing experimental evidence to the use of bovine bone collagen in bone tissue repair applications. Afterwards that biomaterial was inoculated with human osteoblasts in order to evaluate its biocompatibility and cells behavior.

\section{Materials and Methods}

\subsection{Materials and Equipment}

Germany CHRIST ALPHA1-4-type freeze-drying machine, low temperature thermostat bath (Shanghai Bilang instrument Co., Ltd. China), Epichlorohydrin (Wuxi Hengao Co., Ltd. China), nano-hydroxyapatite (Shanghai Hualan Co.,Ltd. China),Japan Shimadzu AGS-J universal material testing machine, CJ88-1 magnetic stirrer (Jiangsu Jintan Hengfen scientific Instrument Factory. China), JMS-840 scanning electron microscope (JEOL CO Japan).

\subsection{Preparation of Biological Composite}

Collagen/HA sample preparation was performed as previously described ${ }^{[6]}$. Briefly, collagen was extracted from bovine tendons, incubated in $1 \%$ sodium hypochlorite for $24 \mathrm{~h}$ at $4{ }^{\circ} \mathrm{C}$ followed by pepsin ( $1 \mathrm{~g} / \mathrm{kg}$ in $10 \%$ acetic acid and $0.2 \%$ chlorhydric acid) for $24 \mathrm{~h}$ at $4{ }^{\circ} \mathrm{C}$. The material was centrifuged at $12,000 \mathrm{rpm}$ with $10 \%$ acetic acid, subjected to "salting-out" $(\mathrm{NaCl})$ and dialyzed against distilled water for 4 days, changing water daily. The collagen was stored at $4{ }^{\circ} \mathrm{C}$. Cortical bovine bone was cleaned, soaked in $10 \%$ sodium hypochlorite for $24 \mathrm{~h}$, rinse $\mathrm{d}$ in water and boiled in 5\% sodium hydroxide for $3 \mathrm{~h}$. The material was further incubated in 5\% sodium hypochlorite for $6 \mathrm{~h}$, washed in water and soaked in 10\% hydrogen peroxide for $24 \mathrm{~h}$. Samples were sintered at $1100{ }^{\circ} \mathrm{C}$ (Mufla EDGCON 5P) for $3 \mathrm{~h}$,pulverized (Marconi MA500) for $4 \mathrm{~h}$, and grains of 200-400 $\mathrm{mm}$ were separated by sieving. Bone 
powders were sterilized at $150{ }^{\circ} \mathrm{C}$ for $2 \mathrm{~h}$, rinsed in tridistilled water and incubated in $1 \%$ phosphoric acid. They were rinsed again in sterile tridistilled water, and sterilized at $100{ }^{\circ} \mathrm{C}$.

$8 \mathrm{~g}$ of bovine bone collagen was dispersed into $192 \mathrm{~g}$ of $6 \mathrm{wt} \% \mathrm{NaOH} / 4 \mathrm{wt} \%$ urea/90 wt \% water mixture stirring for $10 \mathrm{~min}$. The mixed solution was agitated at $-20{ }^{\circ} \mathrm{C}$ for $48 \mathrm{~h}$, then it could obtain a transparent bovine bone collagen solution with a concentration of $4 \mathrm{wt} \%$. The prepared bovine bone collagen solution was stored at $-20{ }^{\circ} \mathrm{C}$ environment. $4 \mathrm{~g}$ SA was dissolved in the same solvent and stirred for $3 \mathrm{~h}$ at room temperature to obtain a $4 \mathrm{wt} \%$ polymer concentration. The bovine bone collagen and SA solutions were mixed rapidly by changing the weight ratio of bovine bone collagen to SA by w/w \% of 0:10 and 5:5, which was coded as No.1 and No.2. ECH (1 ml) as a cross-linker and nanohydroxyapatite $(400 \mathrm{mg})$ were added to the bovine bone collagen/SA mixture $(10 \mathrm{~g})$. The resultant mixtures were stirred at $25{ }^{\circ} \mathrm{C}$ for $4 \mathrm{~h}$ to yield a homogeneous solution, and then reacted at $60{ }^{\circ} \mathrm{C}$ for $2 \mathrm{~h}$. Preparation of solidifying liquid: The $5 \mathrm{wt} \% \mathrm{CaCl}_{2}$ and $5 \mathrm{wt} \% \mathrm{HCl}$ solution were formulated into a uniform mixture. Adding a certain amount of solidifying liquid in the molds, and then the two groups of mixture were put in a mold to solidify at the same time. Cured for 30 minutes, the two groups of gel-like solid were placed in dialysis bag washed to neutral. Put the neutral gel-like solid into $-80{ }^{\circ} \mathrm{C}$ refrigerator for $12 \mathrm{~h}$. The two groups of gel-like solid were placed in a freeze drier $\left(-52{ }^{\circ} \mathrm{C}\right)$ lyophilized for $48 \mathrm{~h}$. Stripping at room temperature to obtain bovine bone collagen/cellulose nanofibers-nanohydroxyapatite composite scaffolds.

\subsection{SEM images of Composite Scaffolds}

The fracture surface (cross-section) of the composite scaffolds were sputtered with gold, and then were observed and photographed under scanning electron microscopic.

\subsection{Determination of Porosity}

Good porosity of the scaffold is conducive to the transport of the blood and cell growth. Nanocomposite scaffolds' porosity were determined by the liquid displacement method. Took a certain volume (V1) and weight (W1) nanocomposite scaffolds of each group, immersed in ethanol $(\rho)$ to saturation, removed and wiped the surface of the liquid with filter paper, measured the weight (W2), and then the porosity was calculated according to the following formula:

\subsection{Determination of Water Retention}

A certain mass of each scaffold was immersed in PBS solution for $24 \mathrm{~h}$. Took the scaffolds out of the PBS solution and weighted its weight (W1), and the scaffolds were freeze-dried, then weighed its weight (W2), so the water retention was calculated according to the following formula:

\subsection{Determination of Degradation Rate}

Vitro scaffold degradation rate is a very important studying parameter, ideal scaffold material can degrade slowly and eventually completely decomposed absorbed or eliminated by the body, gradually replaced by the newly generated tissue. Weighed two groups of certain quality scaffolds (W1), placed $2 \mathrm{mg} / \mathrm{mL}$ lysozyme in PBS solution ( $\mathrm{pH} 7.4$, temperature $35{ }^{\circ} \mathrm{C}$ ), respectively took the scaffolds out of the solution in one week, two weeks, three weeks, four weeks, five weeks, six weeks. Then washed them with distilled water, freeze-dried and re-weighed (W2 ) repeatedly. Therefore, the calculation formula of degradation rate is: 


\subsection{Biomechanical Testing}

Scaffold's mechanical characteristic is an important parameter. The scaffold's maximum load were measured by the universal testing machine. Each scaffold material were cut into $10 \mathrm{~mm}$ $\times 5 \mathrm{~mm} \times 5 \mathrm{~mm}$ size. Tensile test at room temperature, specimen length is $5 \mathrm{~mm}$, and a tensile speed of $2 \mathrm{~mm} / \mathrm{min}$. We calculated modulus of elasticity after measuring the maximum load values of the scaffold material $(\mathrm{X} \pm \mathrm{S}, \mathrm{n}=5)$.

\subsection{Statistical Analysis}

Used SPSS22.0 software package for data analysis. T test was used for statistical analysis. Differences were considered statistically significant when the p-value was less than 0.05 . The results were represented with $\mathrm{X} \pm \mathrm{S}$.

\section{Results}

\subsection{The Test Results of Two Groups}

Scanning Electron Micrographs can be seen from Fig.1. Pore size is shown in Table One. Porosity can be seen from Table 2 , the porosity of No.1 and No.2 were $(91.65 \pm 1.75) \%$ and $(85.42 \pm 1.48) \%$ respectively. The higher the porosity, proved more conducive to cell growth. After statistical analysis, the difference of porosity between the two groups were statistically significant $(P<0.05)$.

Water retention can be seen from Table2, the water retention of No.1 and No.2 were $(97.44 \pm 0.98) \%$ and $(91.36 \pm 0.77) \%$ respectively. By statistical analysis, the difference of water retention between the two groups were statistically significant $(P<0.05)$.

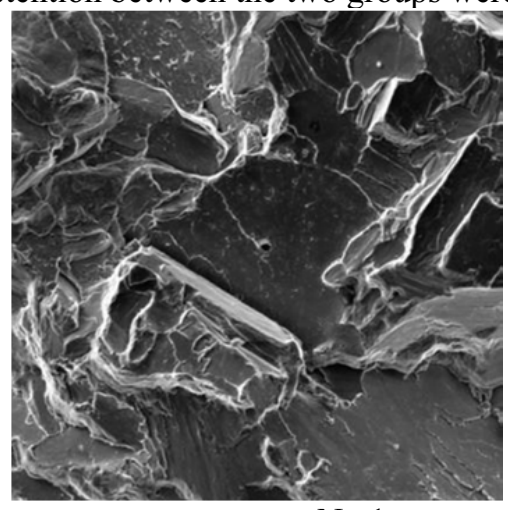

No.1

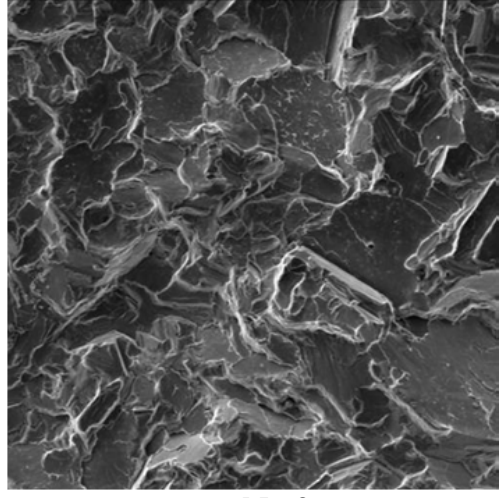

No.2

Fig.1 The SEM images of two groups $(100 \times)$

TABLE 1 DIMENSIONS OF THE PORES OF THE TWO GROUPS OBSERVED ON THE SURFACES OF SECTIONS

\begin{tabular}{ccc}
\hline Specimen & \multicolumn{2}{c}{ Pore size $(\mu \mathrm{m})$} \\
\cline { 2 - 3 } & $\begin{array}{c}\text { Rang } \\
\text { (minimum-maxmum) }\end{array}$ & $\begin{array}{c}\text { Average } \\
\text { (Mean } \pm \text { Standard deviation) }\end{array}$ \\
\hline $\begin{array}{c}\text { No.1 } \\
(0 \% \text { bovine bone } \\
\text { collagen })\end{array}$ & $88.7-160.4$ & $133.4 \pm 13.5$ \\
\hline $\begin{array}{c}\text { No. } 2 \\
(50 \% \text { bovine bone } \\
\text { collagen })\end{array}$ & $157.5-271.3$ & $221.7 \pm 16.8$ \\
\hline
\end{tabular}


TABLE 2 THE POROSITY AND WATER RETENTION OF TWO GROUPS（\%）

\begin{tabular}{ccc}
\hline & Porosity & Water retention \\
\hline $\begin{array}{c}\text { No.1 (0\% bovine bone } \\
\text { collagen) }\end{array}$ & $91.65 \pm 1.75$ & $97.44 \pm 0.98$ \\
\hline $\begin{array}{c}\text { No.2 (50\% bovine bone } \\
\text { collagen) }\end{array}$ & $85.42 \pm 1.48$ & $91.36 \pm 0.77$ \\
\hline
\end{tabular}

Two material were put into PBS solution which Containing $2 \mathrm{mg} / \mathrm{mL}$ lysozyme, measuring degradation rate in vitro after 1, 2, 3, 4, 5, 6 weeks respectively. The results were shown in Fig.2. After statistical analysis, the difference of degradation rates between the two groups were statistically significant $(P<0.05)$.

Elastic modulus is equal to the stress/strain. The results were shown in Table 3 . The differences between the two groups were statistically significant. The tensile propertiesthe of the group which containing $50 \%$ Bovine bone collagen have better performance than that without bovine bone collagen.

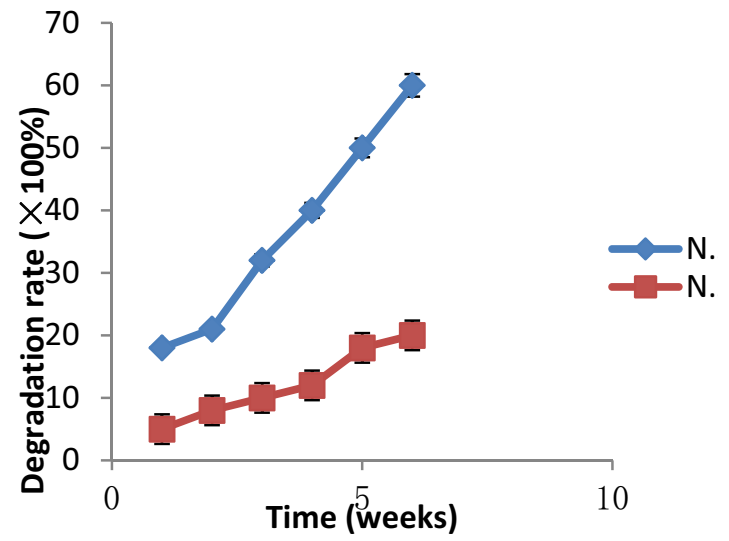

Fig.2 Comparison of degradation rate of two groups

TABLE 3 MECHANICAL PROPERTIES OF THE TWO GROUPS

\begin{tabular}{ccc}
\hline & Maximum lord $(\mathrm{N})$ & Young modulus (MPa) \\
\hline $\begin{array}{c}\text { No.1 ( } 0 \% \text { bovine bone } \\
\text { collagen })\end{array}$ & 11.947 & $7.09 \pm 0.29$ \\
\hline $\begin{array}{c}\text { No.2 (50\% bovine bone } \\
\text { collagen })\end{array}$ & 65.178 & $35.485 \pm 0.36$ \\
\hline
\end{tabular}

\section{Discussion}

It has been the thorny issue of clinical to repair bone defects caused by tumors, trauma or deformity. Severe bone defects, the bone tissue can not be self-repair. Meanwhile, the rapid development of modern tissue engineering has opened up new ways to treat bone defects. So it is a trend to find a bone substitute material autologous to repair bone defect.

The biomaterial analyzed and characterized here had some properties and characteristics reported by the literature as ideal for enhancing the generation of a new bone tissue. Ideal tissue engineering scaffold material should have the following conditions: (1) has good biocompatibility. (2) osteoinductive and osteoconductive. (3) biodegradability and degradation adjustability. (4) suitable mechanical strength. (5) open porosity. (6) plasticity and 
workability $^{[5]}$. In this study, two groups of scaffolds were prepared, which No.1 group does not contain bovine bone collagen, while No.2 group containing $50 \%$ bovine bone collagen. Two groups contain the same amount of hydroxyapatite to improve stent strength. Groups contain cellulose nanofibers, sodium cellulose nanofibers non-toxic, non-immunogenic, preferably the viscosity, hydrophilic, are able to provide a good three-dimensional cells and to maintain a good environment for the growth shape, thus completing the demineralized bone matrix modeling. Studies have shown that the need for porous scaffolds, the porosity of $85 \%$ or more, is conducive to cell adhesion. Meanwhile, scaffold material should have good biodegradability. The experimental results showed that: composite scaffold by freeze-drying showed spongy, with a high moisture content, and hardness, not easy to be broken. Judging from the appearance of the two groups, they have good plasticit, can be prepared to more regular shape. Scanning electron microscopy showed No.2 group aperture greater than No.1 group. The average pore size of No.2 group was about $210 \mu \mathrm{m}$, more conducive to the growth of cell adhesion. Except by the pore size of freeze-dried outer, may also be set with No.2 alkaline ions in the dialysis processes. Porosity and moisture content in the two groups were $85 \%$, while the porosity No. 2 group and water content below No.1 group, but still able to meet the needs of cell growth. No.2 group was significantly lower than the degradation rate No.1 group, indicating that degradation of bovine bone collagen material can improve the stability of the bone defect. It is more conducive to play a supporting role substitute materials, while the degradation of the material is stable in favor of bone formation. It is an important indicator to evaluate whether the scaffolds practical. The experimental results showed that: bovine bone collagen scaffolds significantly improved biomechanical properties. No. 2 group is higher than No. 1 group in maximum stress, strain and elastic modulus. In summary, bovine bone collagen/Cellulose nanofibers-hydroxyapatite composite scaff-olds have shown its superiority in tissue engineering materials. But its actual effect of bone defect repair remains to be further through animal bone defect repair in vivo experiments confirmed. Bovine bone collagen is a resource-rich, biological material with excellent performance. Because of its intrinsic antibacterial activity and other fine features, it shows a great prospect in repairing bone defect filled with bone tissue engineering scaffolds.

\section{Acknowledgements}

This work is supported by 2014 Educational Commission of Anhui Province of China (NO.KJ2014A243) and 2016 The Key Program in the Youth Elite Support Plan in Universities of Anhui Province (NO.gxyqZD2016304).

\section{References}

1. P. Ducheyne, Q. Qiu, Bioactive ceramics: the effect of surface reactivity on bone formation and bone cell function, Biomaterials. 20(1999) 2287-2303.

2. D. Green, D. Walsh, S. Mann, R.O.C. Oreffo, The potential of biomimesis in bone tissue engineering: lessons from the design and synthesis of invertebrate skeletons, Bone . 30(2002) 810-815.

3. J.A. Sowjanya, J. Singh, T. Mohita, et al, Biocomposite scaffolds containing chitosan/alginate/nano-silica for bone tissue engineering, Colloids and Surfaces B: Biointerfaces. 109(2013): 294-300.

4. P. T. Sudheesh Kumar, C. Ramya, R. Jayakumar, et al, Drug delivery and tissue engineering applications of biocompatible pectin-chitin/nano $\mathrm{CaCO}_{3}$ composite scaffolds, Colloids and Surfaces B: Biointerfaces, 106(2013)109-116. 
5. J.S. Xie, J. Sun, Y.L. Li , et al, Experimental Research of the Novel Macroporous Chitin /Alginate-nanohydroxyapatite Composite Scaffolds, Progress in Modern Biomedicine, 10(2014)1834-1838.

6. C.V.M. Rodrigues, P. Serricella, A.B.R. Linhares, et al, Characterization of a bovine collagen-hydroxyapatite composite scaffold for bone tissue engineering, Biomaterials, 24(2003) 4987-4997. 